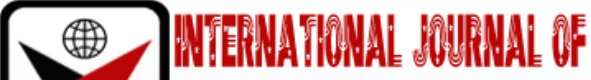 \\ בmas
}

ISSN 2278-0211 (Online)

\section{Population Growth as a Socio-Economic Factor Affecting Small Scale Sugarcane Farming in Bumula Sub County, Bungoma County, Kenya}

\author{
Akhayere Adrum Shikuku \\ Graduate Student Researcher, Department of Agribusiness Management and Extension, \\ Masinde Muliro University of Science and Technology, Kenya
}

\begin{abstract}
:
The sugar industry in Kenya is mainly supported by the small holder farmers who supply $92 \%$ of the sugarcane milled in the country. This paper considers the effect of population growth on plot sizes of arable land as a socio-economic factor that affects sugarcane farming among the small-scale farmers of Bumula Sub County, Bungoma County Kenya. The study was based on three objectives: to evaluate how population growth affects plot size of the arable land; to establish if small scale farmers know the measures for birth control and the available technology used to increase yields. Descriptive survey method was used in the study because the researcher was to collect data from members of a given population with respect to one or more variables in the study. A total of 327 farmers were sampled using stratified random sampling while five extension officers and three area leaders were selected using purposive sampling. Data was collected using interviews for the extension officers and area leaders while questionnaires for the farmers. Quantitative data was analyzed using frequencies and percentages. Qualitative data was transcribed, categorized and reported in themes relevant to the study. Findings from this research have provided recommendations to the concerned stakeholders in the sugar industry so that necessary control measures can be taken. The findings are of great importance to the sugarcane farmers, sugarcane millers, and the sugar industry in Kenya. Appropriate recommendations have been made to relevant bodies for action.
\end{abstract}

Keywords: Population growth, socio economic factor, small scale farming, sugarcane

\section{Background to the Study}

Sugarcane farming has been practiced around the world over since the Persian soldiers discovered the 'reeds that produced honey without bees' along river Indus between the 6th and 4th Centuries in India. Since then, sugarcane farming has been practiced in various tropical regions of the world with the major driver of the industry being the world's increasing demand for sugar. This has led to the expansion of arable land under sugarcane cultivation, with a myriad of problems presenting themselves ecologically, socially and economically. The main driver behind the expansion of land under sugarcane farming and increasing sugarcane monoculture is the constant rise in the world's demand for sugar (Oyugi, 2016).

Mozambique has become one of the largest South African sugar producers by turning to sugarcane farming as a means to involve local population while extending their agricultural potential and increasing Mozambican's sugar exports. It has been observed that sugarcane farming is regarded as one of the ways to lift the poor out of their poverty by providing them with loans, infrastructural (irrigation technology) support and know-how support and income security Ernst, (2012).

In Zambia, government development objectives have prioritized the commercialization of the smallholder sector throughout grower schemes as a way to integrate poor farmers in rural areas into the national economy $(F A 0,2009)$.

Sugarcane growing in Kenya plays a very important role in the country's economy. The subsector's contribution to the economy is as important as that of crops like tea, coffee, horticulture, and maize. The sugar sub-sector contributes about $15 \%$ of the agricultural gross domestic product (GDP). Agriculture is the main stay of Kenya's economy, supporting at least $25 \%$ of Kenyan population. This population relies directly or indirectly on the sub-sector for their livelihoods Muli, (2016).

The sugar subsector is a source of lively hood of about 6 million Kenyans and cultivated by about 200,000 small scale farmers. Kenya's annual sugar production ranges from 450,000 to 550, 000 metric tons of sugar. This does not meet the country's annual demand and consequently sugar is imported. Domestic demand for sugar is 760,000 tons, which leaves a deficit of up to 200,000 tons that is met by imports from regional sugar producers. In July, 2008 the government of Kenya cancelled the licenses of all its 55 sugar importers citing miss-use of import licenses, tax evasion and those imports were hurting local farmers, KSB, (2015). 


\section{Population Growth Effect on Plot Sizes}

Growing population has aggravated the stress on land and other natural resources to meet the growing demands for food, fiber, fodder, and fuel. The land use changes in Brazil for producing soybean and timber and rising cattle have been the main drivers in the deforestation of the Amazon Nepstadet al (2014).

Farm size is defined as the total number of hectares under cultivation in the main season and does not include rented out or fallow land Sheahanet al., (2014).

Anna L.J., Jacob R.G., and Raymond J.G.M, (2014), stated that higher rural population density is associated with smaller farm sizes, and thus farm income declines as population density increases.

While large parts of sub- Saharan Africa (SSA) can be characterized as land abundant, scarcity of farm land is becoming an issue in a large proportion of the continent as population grows. This issue is particularly critical in densely populated rural areas where off-farm employment opportunities are limited and continued dependence on low-input and low out-put traditional agriculture cannot sustain the people's livelihood Headeyet al, (2014).

Ariana K., (2014) stated that land access is a significant determinant of whether a house hold will be food secure, less vulnerable to risks and shocks, and earn a living above poverty line. They also established that in Malawi a 100 person increase in population density reduces mean farm size by about $10 \%$. Land being regarded as key input in poverty reduction and food security the decline in farm size associated with land holding points to a troubling picture. In their study on food policy in Malawi (Food Policy Journal volume 48,2014) they state that increase in population density is associated with reduced farm size, and it lowers agricultural wage rates.

Mbuyawzweet al., (2012), in Swaziland observed that large scale farmers get highest level of yields, with the medium and small-scale farmers coming second and third respectively. They were mainly studying the relationship between the amounts of cane harvested in relation to farm size.

Wanyonyi, (2016) notes that about $80 \%$ of Kenya's population lives in rural areas, and most of these households are dependent on agriculture for a large part of their livelihood. Increased productivity of the millions of people engaged in agriculture is clearly required for living standards to rise. But since Kenya's arable land mass is largely fixed and already under cultivation, expansion of cropped area is not a realistic option to increase the livelihoods of Kenya's rural population, growing at $3.34 \%$ per year.

Kweyu (2013) revealed that small scale cane farming has been affected by the reduction in farm size. Initially farmers used to own large tracks of land which sometimes lay fallow. This was a perfect opportunity for the excess land to be utilized under cane farming. Currently most of the fields have been subdivided for distribution among the offspring; others have been leased while the others have been subdivided for sale. Due to delays in payments by the companies against the immediate financial needs, some farmers have opted to lease their land to other farmers or businessmen.

\section{Methodology}

\subsection{Design}

The study used descriptive survey method.

\subsection{Population}

Population was 335.

\subsection{Sample and Sampling}

It sampled 327 small scale farmers by stratified random sampling, 5 extension officers, and 3 area leaders were sampled purposively.

\begin{tabular}{|c|c|c|c|c|}
\hline Description & Target Population & Sample Size & $\mathbf{\%}$ & Sampling Technique \\
\hline Contract farmers & 2671 & 327 & 97 & Stratified random sampling \\
\hline Extension officers & 12 & 5 & 1.4 & Purposive sampling \\
\hline Area leaders & 5 & 3 & 0.8 & Purposive sampling \\
\hline
\end{tabular}

Table 1: Target Population and Sample Size

\subsection{Data Collection}

Data for this study was collected by use of questionnaires, interview schedules. 


\section{Results}

\begin{tabular}{|c|c|c|c|c|}
\hline \multirow[t]{2}{*}{ ASPECT } & \multicolumn{2}{|c|}{ AGREE } & \multicolumn{2}{|c|}{ DISAGREE } \\
\hline & $f$ & $\%$ & $f$ & $\%$ \\
\hline $\begin{array}{l}\text { 1. Generally, there is reduction of sugarcane } \\
\text { plot size }\end{array}$ & 196 & 59.9 & 131 & 40.1 \\
\hline 2. Arable land reduces with growing population & 236 & 72.2 & 91 & 27.8 \\
\hline $\begin{array}{l}\text { 3. Sugarcane plots have been subdivided to } \\
\text { children }\end{array}$ & 216 & 66.1 & 111 & 33.9 \\
\hline $\begin{array}{l}\text { 4. Culture contributes to the growing } \\
\text { population }\end{array}$ & 249 & 76.1 & 78 & 23.9 \\
\hline $\begin{array}{l}\text { 5. Sugarcane farming is affected by growing } \\
\text { population }\end{array}$ & 209 & 63.9 & 118 & 46.1 \\
\hline $\begin{array}{l}\text { 6. Sugarcane farming is an advantage to the } \\
\text { to the growing population }\end{array}$ & 169 & 51.7 & 158 & 48.3 \\
\hline $\begin{array}{l}\text { 7. Physical development in Bumula is due to } \\
\text { the growing population }\end{array}$ & 214 & 65.4 & 113 & 34.6 \\
\hline $\begin{array}{l}\text { 8. There is a reduction of sugarcane land } \\
\text { Area in your block. }\end{array}$ & 258 & 78.9 & 69 & 21.1 \\
\hline $\begin{array}{l}\text { 9. Land subdivision had reduced sugarcane } \\
\text { Production }\end{array}$ & 75 & 23.8 & 249 & 76.2 \\
\hline 10. I desire to control birth & 186 & 56.9 & 141 & 43.1 \\
\hline $\begin{array}{l}\text { 11. You are aware of technology to increase } \\
\text { Food production }\end{array}$ & 256 & 78.3 & 71 & 21.7 \\
\hline $\begin{array}{l}\text { 12. There is need for new technology to } \\
\text { Increase sugarcane production }\end{array}$ & 248 & 75.8 & 79 & 24.2 \\
\hline
\end{tabular}

Table 2

Results from Table 4.8 revealed the following. Respondents gave their take on whether there was a general reduction in sugar plot sizes. 196 (59.9\%) of the respondents indicated that it is true that the plot sizes have reduced because the land has been sub divided to children when they start families and also it is a cultural demand that children must be given inheritance especially land for the livelihood of the future families. Interviews with the extension officers and area leaders revealed that sons leave the original homes to go and start their compounds outside the nuclear family within the same parcel of land. This has contributed to the shrinking of land. This confirms the findings by Bordonalet al., (2018) that asserts that growing population has aggravated the stress on land and other natural resources to meet the growing demands for food, fiber, fodder, and fuel. On the other hand, 131(40.1\%) of the respondents indicated that it is not true because most of the parents are unwilling to give out land as they fear children selling it. This implies that as families expand the land has to be sub divided despite some parents being unwilling to do so. This out rightly implies that sugarcane plot sizes reduce. This is particularly so because the plots are used for other purposes apart from sugarcane farming such as growing food crops and constructions.

Secondly, respondents expected to affirm whether or not arable land reduces with growing population. Results indicate that $236(72.2 \%)$ of the respondents agreed that arable land had reduced with the growing population. They added that this was due to the new families coming up. 91(27.8\%) respondents disagreed. On the other hand,

\section{Conclusion}

The research established that generally, plot sizes had reduced due to growing population. As population increased there was need for increasing food crop production and constructions. These affected sugarcane farming as the plots were reducing as well as a result of continuous subdivision of land. Equally, population growth was attributed to cultural practices such as polygamy, wife inheritance, early marriages, and lack of health reproductive education. This can be mitigated by reproductive health education and increasing literacy levels.

Despite the reducing plot sizes, it was clear that farmers are still interested in sugarcane farming as it is a beneficial venture to the population being the only viable commercial crop in the region because of the readiness of the market. In addition, both population growth and sugarcane farming had enabled the region realize physical development as this brought about the demand for social amenities and the response to Cooperate Social Responsibility by the mills. In addition, the majority wished to control birth but a few were reluctant to control because of their cultural belief and their faiths. There is therefore need for reproductive health education and sensitization of family planning.

Finally, farmers had been equipped with some current technology to increase food production. This included techniques such as organic farming, green house technology, intercropping and mixed farming. Farmers also suggested on technologies which they knew to be used in sugarcane production on reducing plots for better yields such as organic farming, use of early maturing varieties, inter cropping, new blends of fertilizers and oxen plough. 


\section{Recommendations}

1. The issue of population growth effect on plot sizes revealed that plot sizes were reducing as population grows. These had a number of implications that leads to the following recommendations:

- Farmers should acquire their own inputs for small plots of 0.2 ha and less since they are uneconomical. Alternatively, a group of farmers should amalgamate their plots for purposes of input supply.

- People should be discouraged from cultural practices that are unproductive and faiths that are detrimental to development.

- Any underutilized chunks of land should be leased off to mills for sugarcane cultivation.

- Institutions with big pieces of land particularly agricultural based institutions should sign a memorandum of understanding with sugar mills so that they can develop sugarcane on those lands.

- National government and County government should deploy social workers on the grass root to sensitize the people on birth control through sound reproductive health education.

- Extension officers should emphasize on the adoption of technologies known to the farmers as well as other new ones so as to increase production on the reducing plot sizes.

- There is need for more research on the level of adoption of technologies and challenges being experienced by farmers.

\section{References}

i. Anna L.J., Jacob R.G., and Raymond J.G.M, (2014). How does population density influenceagricultural intensification and productivity? Evidence from Ethiopia. Food Policy 2014, volume 48.Pages 142-152.

ii. Ariana K., (2014). Drawing Links Between Food Security and Land Rights I an Era ofGlobalization. (Unpublished Thesis, University Of Toronto).

iii. Dubb, A., (2015). Dynamics of decline in small-scale sugarcane production in South Africa:

iv. Evidence from two 'rural' wards in the umfolozi region. Land Use Policy 48(362), 362-76. Doi: 10.1016/j.landusepol.2015.06.029

v. Kabubo J.M., Kabara M.,(2015). Climate change and Food security in Kenya.(Kenya Institutefor public Policy Research Unit. Nairobi Kenya (Unpublished paper).

vi. Kumar, Teshu\& Singh, H.L. \&Jawla, S.K. \&Sachan, Sharad. (2014). Cost and returns of sugarcane production at different size groups of farms in district Meerut (U. P.), India. 19.561-565.

vii. Mishra K., A., Pramod K.(2018). Risk of preference and Contract farming: Impact on foodsecurity in India. Applied Economic Perspective Rsearch Review 40: 353-378.

viii. Ministry of Agriculture, Livestock, Fisheries and Irrigation (2019). Agricultural Transformation and Growth Strategy (ASTGS) 2019-2029. Republic of Kenya.

ix. PereraM.S.Abeynayake,N.R and Peiris, T.D.G.J. (2010). Socio economic factors affectingtechnology and adoption level of sugar cane in rain fd sector in Sevenagala,Sri Lanka.

x. Ravath G., (2014). Trend Analysis of sugar cane area, production, and productivity, in Andhra Pradesh. Unpublished Thesis Achrya N.G. Ranga agricultural University.

xi. Ricardo de Oliveira Bordonal,João Luís Nunes CarvalhoRattan Lal,Eduardo Barretto de Figueiredo(2018). Sustainability of sugarcane production in Brazil.

xii. Sarvanan A., (2016). Indian Journal of Economics and Development Vol.4 Issue 8 August 2016.

xiii. See P. J. and Woodhouse P., (2017). 'Crisis and Differentiation among Small-ScaleSugar Cane Growers in Nkomazi, South Africa' (Journal of Southern African Studies, 43, 3(2017), pp. 535-49).

xiv. V. Rocca, (2014). 'The Gendered Implications of the Expansion in Commercial Sugarcane

xv. Production:A Case of Contract Farming in Magobbo, Zambia' (MA unpublished thesis, Carleton University, 2014). 